Public Abstract

First Name:Phat

Middle Name:Tien

Last Name:Do

Adviser's First Name:Zhanyuan

Adviser's Last Name:Zhang

Co-Adviser's First Name:

Co-Adviser's Last Name:

Graduation Term:SS 2016

Department:Plant, Insect and Microbial Sciences

Degree:PhD

\title{
Title:GENETIC ENGINEERING OF SORGHUM AND SWITCHGRASS FOR IMPROVED BIOFUEL PRODUCTION
}

Biofuels, energy sources generated from biomass, have been seen as a potential route to meet energy demand and avoid political instability and environmental issues worldwide. Switchgrass has been considered as an excellent feedstock for biofuels due to the high cellulosic content, wide adaptation as well as the lower input energy for production. Sorghum is the fifth most important crop in the world for human staple food and also a versatile feedstock for grain, sugar, and biomass production. In current study, we demonstrated that expression of the Zea mays gibberellin 20-oxidase (ZmGA20ox) cDNA in switchgrass improved biomass production. Under greenhouse conditions, selected transgenic plants exhibited longer leaves, internodes and tillers, which resulted in 2 -fold increased biomass. This is the first parallel report on the switchgrass biomass increase through genetic engineering approach. Our results suggest that the employment of ectopic ZmGA20ox, or selection for natural variants with high level expression of endogenous GA20ox are appropriate approaches to increase biomass production of switchgrass and possible other monocot biofuel crops. Additional contribution of this study is to optimize sorghum regeneration and transformation processes using standard binary vectors and bar gene as a plant selectable marker. The optimized transformation process enables reproducibly to achieve over $14 \%$ transformation frequency, the highest transformation efficiency through Agrobacterium-mediated transformation among the public laboratories. Of randomly analyzed independent transgenic events, 40$50 \%$ events carried a single copy of integrated T-DNA. The system developed here should be beneficial to sorghum biology study and genome exploration including genome editing. 